\title{
Supramitral congenital mitral stenosis: a rare case
}

\author{
Meshram R.M. ${ }^{1}$, Bhongade S. ${ }^{2}$, Chaurasia S. ${ }^{3}$ \\ ${ }^{1}$ Dr. Rajkumar M. Meshram, Associate Professor, ${ }^{2}$ Dr. Swapnil Bhongade, Assistant Professor, ${ }^{3}$ Dr. Sandeep Chaurasia, \\ Senior Resident, Cardiology, Department, S.S.H. Nagpur, Department of Paediatrics, Govt. Medical College, Nagpur, \\ Maharashtra, India.
}

Corresponding Author: Dr. Rajkumar M. Meshram, Associate Professor, Department of Paediatrics, Govt. Medical College \& Hospital, Nagpur (M.S.). E-mail: dr_rajmeshram@rediffmail.com

\begin{abstract}
Congenital mitral stenosis (CMS) is a rare congenital heart disease and is anatomically divided into typical mitral stenosis, hypoplastic congenital mitral stenosis, supravalvalar mitral stenosis, parachute mitral valve and subvalvar stenosis. A 40 days old male prematurely delivered, very low birth weight was symptomatic since neonatal period was admitted with respiratory distress and not gaining weight. On examination, he had respiratory distress and tachycardia without dysmorphism. He had pansystolic murmur and pulmonary hypertension. Echo cardiography revealed supramitral membrane with mitral stenosis and ventricular septal defect. Clinically congenital mitral stenosis is difficult to diagnose as coexisting intracardiac lesions may mask or unmask the disease.Despite great advances in surgical technique, surgical treatment of CMS is still challenge able particularly in neonates and small infants.
\end{abstract}

Key words: Congenital heart disease, Congenital mitral stenosis, Echocardiography

\section{Introduction}

Mitral valve formation begins during the fourth week of gestation of life. Anatomically, mitral valve apparatus is composed of annulus, leaflets, chordae, and papillary muscle. Isolated congenital mitral stenosis (CMS) is rare and the reported incidence in autopsy series with congenital heart disease is about $0.6 \%$ and in clinical series about $0.4 \%$ [1,2]. Clinically, anatomic types of congenital mitral valve stenosis divides into typical mitral stenosis, hypoplastic congenital mitral stenosis, supravalvalar mitral stenosis, parachute mitral valve and subvalvar stenosis which is also known as mitral arcade [3]. In neonates, congenital mitral stenosis is unlikely to present as an isolated lesion; rather it is frequently part of a complex or syndrome involving the left heart. CMS most commonly exist in association with left heart under development, coarctation of aorta, subvalvar aortic stenosis, atrial septal defect, ventricular septal defect with or without pulmonary stenosis, shone's complex and variable degrees of hypoplastic left heart syndrome $[4,5,6]$. Here, we describe an infant with supramitral congenital mitral stenosis with ventricular septal defect.

\section{Case Report}

A 40 days old male infant was admitted with fever, cough/cold and difficulty in respiration. He also had history of feeding difficulty and not gaining weight adequately. He was born prematurely (32 weeks of gestation), first of birth order through vaginal delivery with birth weight 1500 grams without any history of maternal teratogenic drug intake, radiation exposure, maternal infection, medical or surgical illness during pregnancy.

He was NICU graduate for prematurity, respiratory distress and feeding difficulty and was advised feeding with nutritional supplementation on discharge. None of his family members had congenital heart diseases or genetic diseases. He was immunized for BCG vaccine and developmentally normal as per age. On physical examination, he had signs of failure to thrive, tachycardia (HR172/min) with normal rhythm and pulses were palpable in all four limbs with systemic

Manuscript received: $8^{\text {th }}$ February 2018

Reviewed: $17^{\text {th }}$ February 2018

Author Corrected: $24^{\text {th }}$ February 2018

Accepted for Publication: $28^{\text {th }}$ February 2018 


\section{Case Report}

blood pressure of $72 / 52 \mathrm{mmHg}$, tachypnea $(60 / \mathrm{min})$ with respiratory distress and oxygen saturation $98 \%$. He had no cyanosis, no facial dysmorphisim, polydactyly or syndactyly.

The examination of cardio vascular system revealed a grade III/VI pansystolic murmur in mitral area and conducted widely to other areas of precordium. The second heart sound had a loud pulmonary component.

The liver was palpable $2 \mathrm{~cm}$ below the right costal margin.

Respiratory system examination revealed crepitations on the right mammary and inframammary area.

The Chest X ray showed a cardiomegaly and pulmonary plethora (Figure 1).

The electro cardiogram revealed sinus rhythm and was suggestive of left atrium and right ventricular hypertrophy.

Echocardiography was diagnostic and showed dilatation of left atrium and right ventricle.

There was a supramitral membrane with reduced mitral valve area $(0.7 \mathrm{~cm} / \mathrm{sq} \mathrm{m})$ and $3 \mathrm{~mm}$ ventricular septal defect.

Severe tricuspid regurgitation and severe pulmonary hypertension were noted (Figure 2A \&2B).

Diagnosis of severe congenital mitral stenosis due to supramitral membrane with severe pulmonary hypertension was confirmed and patient was referred to cardiothoracic surgeon for further management.

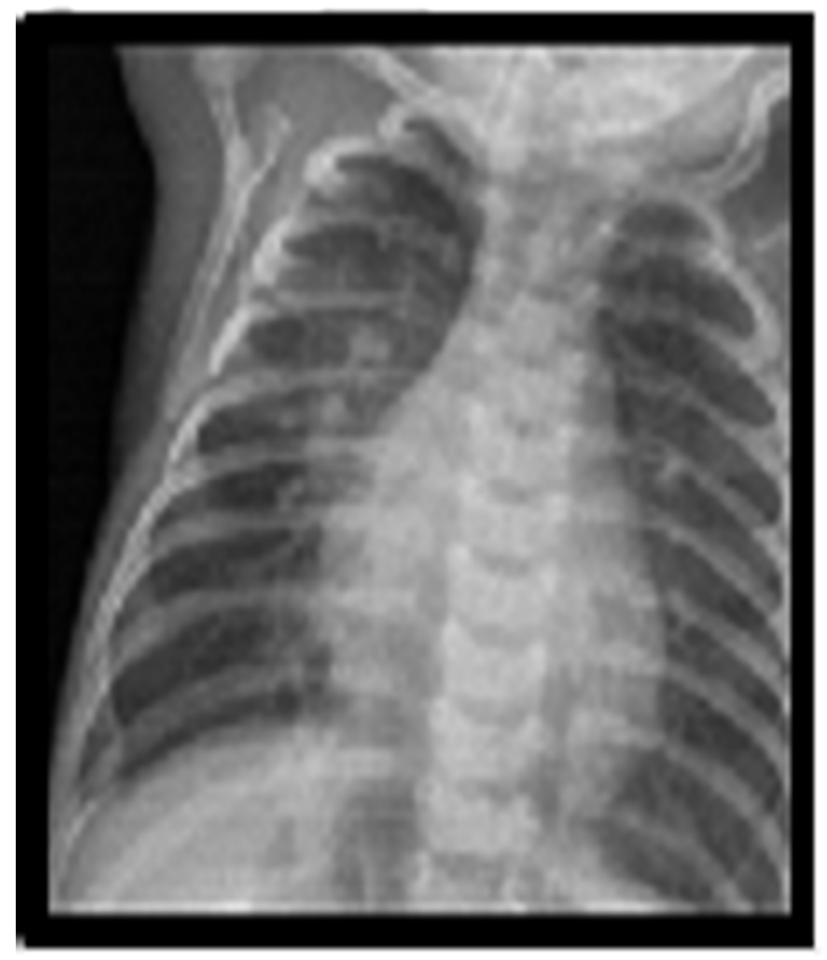

Figure-1: Chest $X$ ray showed cardiomegaly and pulmonary plethora 


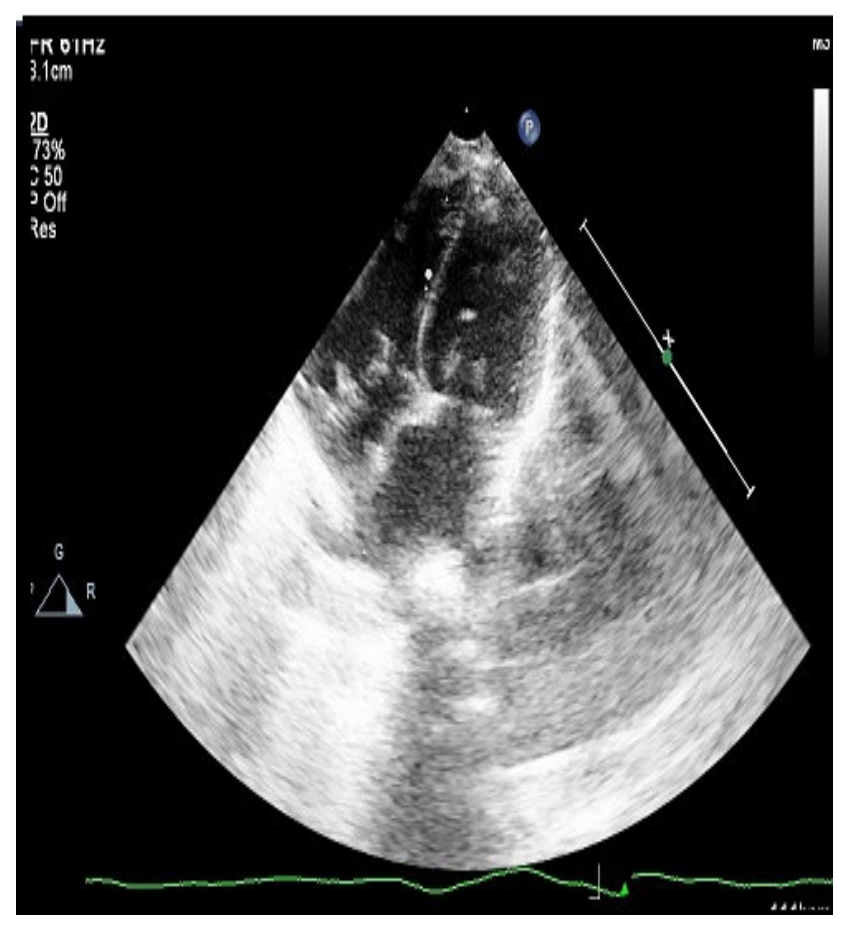

Figure- 2A Echocardiography showed supramitral valve ring and pressure gradient

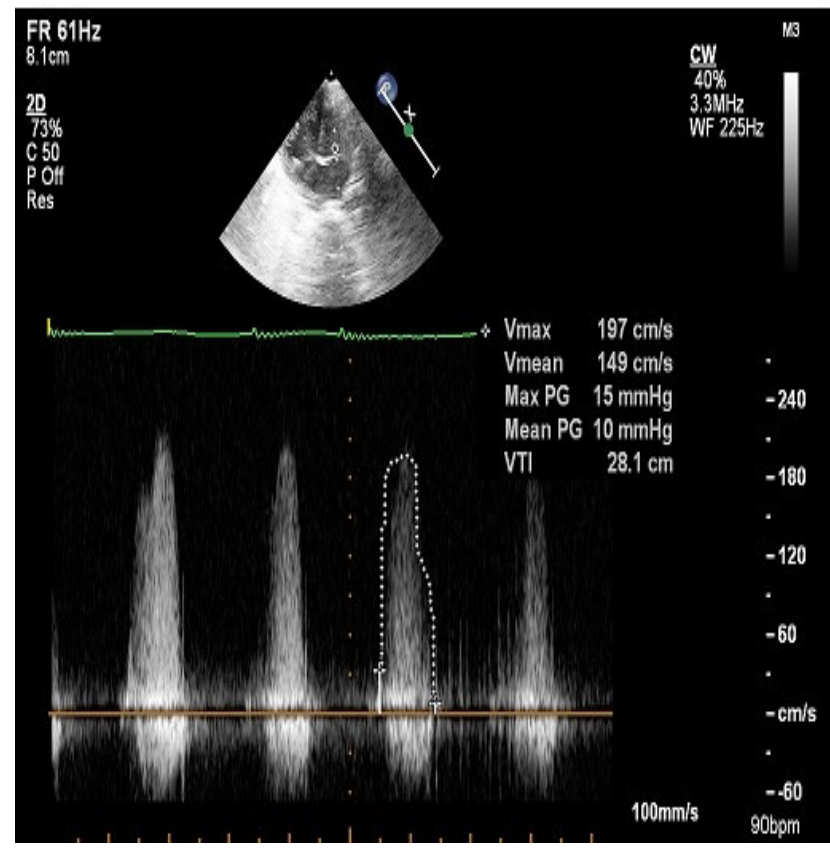

Figure- 2B: Echocardiography showed supramitral valve ring and pressure gradient 
Case Report

\section{Discussion}

Congenital anomalies of the mitral valve represent a wide spectrum of lesions that are often associated with other congenital anomalies. The integration of mitral valve apparatus (annulus, leaflets, chords and papillary muscle) along with the freedom from supravalvular pathologic function (supramitral ring) and left ventricular pathologic function (hypoplastic ventricle) is essential for normal function.

Congenital mitral stenosis is a rare entity; reported incidence on clinical series with congenital heart disease is 0.21 to $0.4 \%[1,2]$ and takes several types. The morphologic identification on echo cardiography and interventional report of 85 infants by Moore $\mathrm{P}$ et al includes stenoticmitral valve with symmetry of papillary muscle (52\%), supravalvar mitral ring $(20 \%)$, double orifice mitral valve (11\%) and hypoplastic mitral valve with asymmetric papillary muscle $(8 \%)$ while $\mathrm{Mc}$ Elhinney DB et al [7] reported typical congenital MS in 78 infants, supravalvar mitral ring in 46 , parachute mitral valve in 28 and double - orifice mitral valve in 11 , with multiple types in around $50 \%$ of patients of series of 108 infants with severe congenital mitral stenosis.

Isolated congenital mitral stenosis is very rare andmost commonly exist in association with left heart underdevelopment, left ventricular outflow tract obstruction and shone complex [4].

Most of the series revealed coarctation of aorta, subaortic stenosis, bicuspid aortic valve, supravalvular aortic stenosis, aortic regurgitation, ventricular septal defect, atrial septal defect, patent ductus arterious, small left ventricle, double outlet right ventricle, pulmonary stenosis and tetralogy of fallot $[2,6,8,9]$.

Coexisting intra cardiac lesions may mask or unmask mitral valve diseases and may frequently increase the complexity of surgical repair.
The etiology of congenital MS remains unknown. However, prevalence of MS in the offspring of family members especially the mother with left ventricular outflow tract obstruction is relatively high.

Clinical presentations of congenital mitral stenosis are dependent on the anatomic variant, severity, associated lesions and age. Pulmonary hypertension and inadequacy of the left heart to support the systemic circulation are the most significant clinical consequences.

For clinical, practical and prognostic reasons congenital mitral stenosis can be categorized into neonatal and nonneonatal. Patients with severe MS may present with respiratory distress from pulmonary edema shortly after birth if a significant atrial septal communication does not exist.

Patients with mild to moderate MS may present after the neonatal period with signs of low cardiac output and $\mathrm{RV}$ failure such as pulmonary infection, failure to gain weight, tachypnea and chronic cough [10].

Physical finding in severe MS reveals diminished peripheral perfusion and pulses, palpable second heart sound (when pulmonary hypertension is present), soft S1in the presence of heart failure and diminished left ventricular filling.

Echo cardiography is the most important diagnostic tool to evaluate patient with congenital MS.

Functional severity of stenosis is based on the widely accepted echo cardiographic definition by the American Society of Echocardiography that stratifies the mean gradient across the mitral valve to mild (mean gradient less than $5 \mathrm{~mm} \mathrm{Hg}$ ), moderate (mean gradient between 5 and $10 \mathrm{~mm} \mathrm{Hg}$ ), and severe (mean gradient more than $10 \mathrm{~mm} \mathrm{Hg})[11]$. 
Case Report

Cardiac catheterization may be required to obtain direct intracardiac pressure measurements, the mitral valve gradient, pulmonary vascular resistance and systemic cardiac output. Asymptomatic patients with mild MS require no significant therapy. Congestive cardiac failure is treated with loop diuretics and potassium sparing diuretics.Digoxin may improve right ventricular function in the setting of pulmonary hypertension.

Interventional therapies for medically refractory congenital mitral valve stenosis depends upon specific mitral valve pathology; percutaneous valvuloplasty, surgical valvuloplasty and mitral valve replacement [12]. Surgical interventions of congenital mitral stenosis are usually postponed until the symptoms appear as a higher surgical risk and an efficient and durable repair are somewhat difficult to achieve due to limited exposure of the valvar and subvalvar apparatus in small structured hearts. Mitral valve replacement is best avoided in infants and small children because of frequent size mismatch between the smallest mechanical valves and the hypoplastic mitral valve annulus. In addition, somatic growth in children leads to the need for subsequent mitral prosthesis replacement.

A recent opinion to surgical management is balloon dilatation, which is appropriate even for infants, with unsuccessful medical management but chances of restenosis reported from various studies [2]. Operative results and long-term outcome are extremely variable and highly dependent on coexisting anomalies $[2,7,8,9]$.

\section{Conclusion}

Clinically congenital mitral stenosis is difficult to diagnose as coexisting intracardiac lesions may mask or unmask the disease. Echocardiography and angiocardiography are important diagnostic tools. Despite great advances in surgical technique, surgical treatment of CMS is still challengeable particularly in neonates and small infants.
Funding: Nil, Conflict of interest: None initiated, Perission from IRB: Yes

\section{References}

1. Collins-Nakai RL, Rosenthal A, Castaneda AR et al. Congenital mitral stenosis. A review of 20 years experiences. Circulation 1977;56(6):1039-1047

2. Moore P, Adartia I, Spevak PJ, Keane JF, Perry SB, Castaneda AR et al. Severe congenital mitral stenosis in infants. Circulation.1994;89(5):2099-2106.

3. Macartney FJ, Bain HH, Ionescu MI, et al. Angio cardiographic/pathologic correlations in congenital mitral valve anomalies. Eur J Cardiol 1976; 4 (2): $191-211$

4. Alghamdi AA, Yadav M,VanArsdell GS. Surgical management of congenital mitral stenosis. Operative Techniques in Thoracic and cardiovascular Surgery $2010 ; 8(4): 273-281$.

5. Venkatesh S, Taksande A, Prabhu SS. Isolated congenital mitral stenosis. JK Science 2009;11(1):53-54.

6. Awasthi NA, Marwah A, Sharma R. Congenital mitral stenosis with ventricular septal defect and pulmonary atresia: a rare association. Indian Heart J.2009;61:113-114

7. Mc Elhinney DB, Sherwood MC, Keane JF, del Nido PJ, Christopher S.D almond, Lock JE. Current management of severe congenital mitral stenosis outcomes of transcatheter and surgical therapy in 108 infants and children. Circulation2005;112(2):707-714.

8. Atik FA, Duncan BW, Rosenthal GL, Kawase I, Joshi R, Mee Roger BB. Surgical treatment of congenital mitral stenosis: medium term results. Rev Bras Cir Cardiovasc 2003;18(4):312-320. 


\section{Case Report}

9. Hollman A, Hamed M. Mitral Valve Disease with Ventricular Septal Defect. Br Heart J. 1965 Mar;27: 274-85.

10. Bruce CJ, Nishimura RA. Clinical assessment and management of mitral stenosis. CardiolClin. 1998 Aug; 16(3):375-403.
11. Baumgartner H, Hung J, Bermejo J, et al. Echo cardiographic assessment of valve stenosis: EAE/ASE recommendations for clinical practice. J Am Soc Echo cardiogr 2009;22(1):1-23.

12. Séguéla PE, Houyel L, Acar P. Congenital malformations of the mitral valve. Arch Cardiovasc Dis. 2011 Aug;104(8-9):465-79. doi: 10.1016/j.acvd.2011. 06.004. Epub 2011 Aug 30.

\section{How to cite this article?}

Meshram R.M, Bhongade S, Chaurasia S. Supramitral congenital mitral stenosis: a rare case. Int J Pediatr Res. 2018;5(2):103-108. doi:10.17511/ijpr.2018.i02.11. 